\title{
Sevelamer and Other Anion-Exchange Resins in the Prevention and Treatment of Hyperphosphataemia in Chronic Renal Failure
}

\author{
Oliver Wrong $^{\mathrm{a}}$ Clive Harland $^{\mathrm{b}}$ \\ ${ }^{a}$ Centre for Nephrology and Department of Physiology, Royal Free and University College Medical School, London,

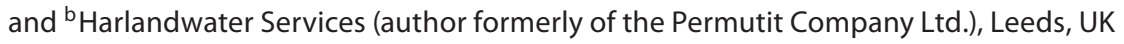

\section{Key Words}

Renal failure - Anion-exchange resin - Weak-base •

Short-chain fatty acids $\cdot$ van der Waals

\begin{abstract}
Sevelamer, or more precisely 'sevelamer hydrochloride', is a weakly basic anion-exchange resin in the chloride form that was introduced in 1997 for the treatment of the hyperphosphataemia of patients with end-stage renal failure, usually those on long-term haemodialysis. The rationale for this therapy was that sevelamer would sequester phosphate within the gastrointestinal tract, so preventing its absorption and enhancing its faecal excretion. Over the succeeding years, large numbers of patients have been treated with sevelamer, and it has fulfilled expectations in helping to control the hyperphosphataemia of end-stage renal failure. However, it is only one of many anion-exchange resins that could be used for this purpose, some of which are currently available for clinical use and are much less costly than sevelamer. Theoretical considerations suggest that some of these other resins might be at least as efficient as sevelamer in sequestering phosphate in the gastrointestinal tract. Neither sevelamer, nor any of these other agents, has been submitted to a proper metabolic balance study to measure the amount of phosphate sequestered by the resin in the bowel, and without this information it is impossible to judge which is the ideal resin for this purpose.
\end{abstract}

Copyright $\odot 2007$ S. Karger AG, Basel

\section{Introduction}

Hyperphosphataemia caused by phosphate retention is almost invariable in patients with end-stage renal failure. It is only partially corrected by intermittent haemodialysis; the majority of patients on this treatment have plasma phosphate levels above the normal range of 0.7$1.5 \mathrm{mmol} / \mathrm{l}$ at the start of each dialysis, with more than a third over the recommended upper limit of $1.8 \mathrm{mmol} / \mathrm{l}$ [1]. This persistent hyperphosphataemia commonly leads to secondary hyperparathyroidism and soft-tissue calcification, which particularly affects the media and intima of the arterial tree. Arterial walls become more rigid, and pulse-wave velocity increases, leading to increased atherosclerosis of the coronary arteries and premature heart disease, which is the major cause of death in patients on long-term haemodialysis [2-6]. Chronic haemodialysis programs for end-stage renal failure have expanded to such an extent $[7,8]$ that there are now over a million patients on haemodialysis worldwide who are at risk of these complications, which also affect many patients with chronic renal failure who are not receiving haemodialysis.

Phosphate in the body is derived in the first instance from dietary phosphorus, which is particularly associated with dietary protein, but attempts to correct the hyperphosphataemia of patients on intermittent dialysis by dietary means have been only partially effective. Treatment has therefore often involved oral administration of

\section{KARGER}

Fax +4161306 1234 E-Mail karger@karger.ch www.karger.com
Oliver Wrong

Department of Physiology and Centre for Nephrology

Royal Free and University College Medical School, Rowland Hill St. London NW3 2PF (UK)

Tel. +44 207637 4740, E-Mail oliverwrong@aol.com 
non-absorbable phosphate-binders, both to prevent the absorption of dietary phosphorus in the gastrointestinal tract and to sequester any phosphate secreted into the bowel lumen and so prevent its reabsorption. The chief phosphate binders used have been colloidal aluminium hydroxide gel and calcium salts (carbonate and acetate), but both have led to long-term complications, aluminium contributing to dementia and bone disease, and calcium salts tending to promote hypercalcaemia and so worsen soft-tissue calcification. More recently ferric and lanthanum salts, which both form insoluble phosphates, have been introduced as phosphate binders but it is still too early to assess their long-term potential.

In 1997 the compound Renage ${ }^{\circledR}$ was introduced as an oral 'phosphate binder', and subsequently given the generic name 'sevelamer' $[9,10]$. Sevelamer was described as 'a non-absorbable, cross-linked polymeric phosphate binder' [11] and 'a novel calcium- and aluminum-free phosphate binder' [12]. Chemically it consists of a crosslinked polyallyl skeleton to which are attached protonated cationic primary and secondary amine groups counterbalanced by exchangeable chloride anions, and sevelamer is therefore capable of the uptake of anions such as phosphate by ion exchange. In chemical terminology sevelamer is thus a weakly basic anion-exchange resin $[13,14]$ although none of the original reports described it as such. Anion-exchange resins, including sevelamer, are hydrated structures in which the polymer chains carrying fixed positively charged ionic groups are counterbalanced by the chemical equivalent of freely mobile anions. Chemical cross-linking of the polymer chains renders the resin rigid and insoluble in most solvents.

Organic anion-exchange resins were first synthesized about 70 years ago, and many different formulations have since been introduced, mainly for commercial use in water purification [14-16]. In clinical medicine they have been used in the treatment of gastric acidity $[17,18]$, in attempts to relieve metabolic acidosis $[19,20]$, to remove bile anions from the body in the management of hyperlipidaemia and cholestasis $[21,22]$, and to sequester intestinal oxalate in the management of enteric hyperoxaluria [23].

Ion-exchange resins can be synthesized by a random co-polymerization condensation reaction between suitable reactants accompanied by the elimination of water (hence the term 'condensation') or hydrogen chloride. Alternatively, a more structured free-radical-induced, or vinyl, co-polymerization between suitable reactants containing double bonds represents the modern approach. In either case the fixed ionic groups are present at the time of polymerization or must be introduced subsequently.
Many different anion-exchange resins are currently available and the purpose of this review is to compare the potential of different resins, including sevelamer, to remove phosphate from the body during gastrointestinal transit and to suggest how this treatment might be improved.

The nature of the 'binding' of a resin to an anion is quite different from the insoluble salts that phosphate ions form with calcium, aluminium and lanthanum, which are almost completely irreversible in biologic systems. Ion exchange on a resin is not normally a classic chemical reaction involving the making and breaking of chemical bonds, but a diffusion-controlled process involving complex physico-ionic interactions $[13,14]$. The exchange of anions is controlled by such basic factors as ion charge, solute concentration, ionic interactions, and the relative hydration energies of exchanging ions [14]. For many poly-atomic anions, for example sulphate and hydrogensulphate, and including all forms of phosphate, the factors governing ion exchange are complex and are described later. Clearly phosphate concentrations in the alimentary tract, and those of other intestinal anions [especially chloride, bicarbonate, and short-chain fatty acid anions (SCFAA)] with which phosphate would be in competition for uptake by a resin, are critical variables in determining a resin's ability to remove phosphate during transit through the gut.

\section{Anion Concentrations in the Gastrointestinal Tract}

\section{Phosphate}

Phosphoric acid is trivalent and the phosphate ion therefore has three acid dissociation exponents or $\mathrm{pK}$ values of approximately 2.2, 7.2 and 12.2: the only one of physiological significance in the gut is the $\mathrm{pK}_{2}$ value of 7.2 for the $\mathrm{H}_{2} \mathrm{PO}_{4}^{-} / \mathrm{HPO}_{4}^{2-}$ dissociation. Adjustment of this value from the known values of ionic strengths of intestinal fluids [24] yields a $\mathrm{pK}_{2}^{\prime}$ value of approximately 7.0. At $\mathrm{pH}$ values below this value, as in the stomach where $\mathrm{pH}$ can be as low as 1.0, phosphate exists predominantly in the monovalent $\mathrm{H}_{2} \mathrm{PO}_{4}^{-}$form; at $\mathrm{pH}$ values more alkaline than 7.0, as in pancreatic fluid with a $\mathrm{pH}$ of up to 8.0, it is predominantly in the divalent $\mathrm{HPO}_{4}^{2-}$ form. Human faeces have a $\mathrm{pH}$ range of 5.6-8.0, averaging about 7.0. At this $\mathrm{pH}$ phosphate exists as monovalent $\mathrm{H}_{2} \mathrm{PO}_{4}^{-}$and divalent $\mathrm{HPO}_{4}^{2-}$ in equal proportions, and so could be ascribed a valency of 1.5. To avoid confusion, in this review we describe chemical concentrations in terms of SI units $(\mathrm{mmol} / \mathrm{l})$, or in electrochemical equivalents $(\mathrm{mEq} / \mathrm{l})$ 
where interactions with ion-exchange resins are concerned, unless otherwise stated.

The dietary intake of elemental phosphorus is in the range of $1-1.5 \mathrm{~g}(32-48 \mathrm{mmol})$ a day, associated particularly with the protein component of food, especially milk and milk products [25-27]. This phosphorus is largely organically bound. In many proteins, for example the milk protein casein, phosphorus is bound as phosphate radicals to the hydroxyl groups of serine and tyrosine. In meat phosphorus is also present as creatine phosphate, as nucleic acids and as the phospholipid of cell membranes. In cereals phosphorus exists largely as phytic acid. Many processed foods contain phosphate esters of starch, added during manufacture to improve storage and freezing quality, which may constitute as much as $30 \%$ of total dietary phosphorus. Organically bound phosphorus is largely converted to inorganic phosphate ion in free solution during proteolytic digestion [28, 29].

In man there are few recorded observations of inorganic phosphate concentrations in the gastrointestinal tract, but most studies have shown values close to those of plasma [30]; 3-7 $\mathrm{mmol} / \mathrm{l}$ in mixed saliva [31-33], 0.90 $\mathrm{mmol} / \mathrm{l}$ in gastric juice [34], $0.74 \mathrm{mmol} / \mathrm{l}$ in pancreatic secretion [35] and $1.8-3.4 \mathrm{mmol} / \mathrm{l}$ at various points in the small intestine [29]. The samples in these studies appear to have been taken from fasting subjects, and the concentrations recorded usually represent total phosphorus rather than phosphate ion, but all investigators emphasize that gastrointestinal phosphorus at various levels in the gut is predominantly in inorganic form. The source of these small amounts of phosphate is not clear; there is no evidence that phosphate is actively secreted into the gastrointestinal lumen, and it may represent phosphate ion which has passively diffused through the mucosa from extracellular fluid, or hydrolysis of the organic phosphorus in intestinal secretions and shed mucosal epithelial cells.

Phosphate absorption in the gut has been little studied in man, but in animals active absorption has been shown only in the small intestine. In rats active absorption is virtually confined to the duodenum and jejunum, whereas in mice it occurs throughout the ileum [36-38]. This difference between species makes it difficult to extrapolate to man, but the few studies available suggest that in man phosphate absorption resembles that in the rat more closely than in the mouse [38].

Although the upper small intestine may be the only site in the gut where an anion-exchange resin might influence intestinal absorption of phosphate, the large intestine plays a critical role in determining the form in which a resin is excreted in the faeces, for the contents of the gut occupy this organ for much longer than other parts of the alimentary tract, and it is here that an anionexchange resin will reach chemical equilibrium with intestinal contents before being expelled from the body. Unfortunately, little is known about the exact chemical state of phosphate in the large intestine. Most studies of faecal phosphorus have involved incineration of faecal organic matter by ashing, and so provide no data on the concentration of diffusible phosphate anion originally present in stool. Studies using in vivo faecal dialysis in healthy subjects consuming their usual diets showed diffusible faecal phosphate values averaging only $2.7 \mathrm{mmol} /$ 1 [39]. This very low concentration is surprising in view of the finding that normal subjects, on their self-chosen diets, excrete some $600-800 \mathrm{mg}(20-26 \mathrm{mmol})$ of phosphorus each day in their faeces [40]. The explanation for this paradox appears to be that most faecal phosphorus is non-diffusible. Its exact chemical form is not known, but in view of the large amounts of calcium present in normal faeces, 350-1,250 $\mathrm{mg}(9-31 \mathrm{mmol})$ per day [41], it seems likely that a major part of this non-diffusible faecal phosphorus is in the form of the extremely insoluble tribasic calcium phosphate salt, $\mathrm{Ca}_{3}\left(\mathrm{PO}_{4}\right)_{2}$.

In view of the very low concentrations of phosphate found at all levels in the fasting gut, the large amounts of phosphate in the faeces of non-fasting subjects must be mainly derived from food residues. An implication of these findings is that the efficacy of an anion-exchange resin in combating hyperphosphataemia must depend more on its ability to sequester dietary phosphate than any phosphate secreted into the alimentary tract.

\section{Other Anions}

In any solution the uptake of an anion by an anionexchange resin is governed by the competition for resin exchange sites from other anions in the medium. The concentrations of other anions in gastrointestinal juices are therefore critical in determining how much phosphate ion is taken up during gastrointestinal transit by an anion-exchange resin such as sevelamer.

Saliva is hypotonic to other body fluids, with only one fifth the osmolality or total anion content of plasma, and concentrations of chloride and bicarbonate averaging only 15 and $6 \mathrm{mmol} / \mathrm{l}$, respectively [30]; there is little opportunity here for phosphate uptake, as the phosphorus in food within the mouth and oesophagus is mainly in organic form.

Within the stomach a resin will be exposed to chloride concentrations of $100-150 \mathrm{mmol} / \mathrm{l}$ in what is virtually 
decinormal hydrochloric acid. The chemical environment changes dramatically when a resin enters the duodenum and is exposed to alkaline pancreatic juice with $\mathrm{pH}$ values as high as 8.0 and bicarbonate concentrations of 62-117 mmol/l [42]. In the rest of the small intestine, $\mathrm{pH}$ is between 6.1 and 7.2; chloride and bicarbonate are the predominant anions, with concentrations averaging about 120 and 3-20 mmol/l, respectively [29].

SCFAAs are the predominant anions in the large intestine [39, 43-45]. They arise from anaerobic bacterial breakdown of food residues, mainly carbohydrate, to short-chain fatty acids (SCFAs), principally acetic, propionic and n-butyric acids. These are weak acids with $\mathrm{pK}$ values of about 4.8. In the large intestine they react with bicarbonate secreted by the mucosa to form the relevant anions. Much of these SCFAAs are absorbed by the mucosa and eventually metabolized in the body to bicarbonate, but sufficient remains in the intestinal lumen to constitute over $75 \%$ of diffusable (averaging $179 \mathrm{mmol} / \mathrm{l}$ [39]) faecal anion. Faecal concentrations of chloride and bicarbonate, the predominant anions in the small intestine, are very much lower than those of SCFAAs, with chloride at $11-23 \mathrm{mmol} / \mathrm{l}$ and bicarbonate $7-40 \mathrm{mmol} / 1[39,45$, 46]. Two other anions in the large intestine that might seriously compete with phosphate for resin are sulphate $(\mathrm{pK}<2)$ and succinate (pK values 4.2 and 5.6$)$, both derived from bacterial breakdown of sulphur-containing aminoacids and carbohydrate residues, respectively. The concentrations of these two anions are in the 1-3 $\mathrm{mmol} / \mathrm{l}$ range $[39,44]$, much lower than SCFAAs, but they are both divalent oxy-anions of low $\mathrm{pK}$, which, as discussed below, are factors favouring their uptake by an anion exchanger.

\section{Uptake of Anions by Resins in the Gastrointestinal Tract}

The anionic composition of the contents of the distal large intestine is critical in determining what anions are attached to an anion-exchange resin when it finally leaves the body in the stool. Resins such as sevelamer reach chemical equilibrium with their environment within minutes [11], so orally administered resin, even if not given in the chloride form, would temporarily be converted to this form in the stomach, and exist predominantly in the chloride form during passage through the small intestine. Bicarbonate ion, because of its high $\mathrm{pK}$ value of 6.1, is unlikely to be taken up avidly by a weakly basic resin such as sevelamer, but if it were it would be readily dis- placed by chloride ion. A resin's exchangeable anion content is likely to be largely replaced by SCFAA (and to a lesser extent by sulphate and succinate) during passage through the large intestine, and it would be excreted predominantly in this form in the stool, with smaller amounts of chloride, bicarbonate and phosphate, reflecting the lower concentrations of these anions in faecal water [39].

However, the anion composition of a resin when it is passed in the stool does not necessarily indicate important anion exchanges occurring at a more proximal level in the gut, particularly in the small intestine where active absorption of phosphate occurs. Although SCFAA is the predominant anion in the large intestine, it is not known to what extent it exists in the human small intestine. Intestinal SCFAA is a product of bacterial metabolism, and though the small intestine has an appreciable microbial flora in its more distal part, bacterial counts here are several orders of magnitude lower than in the large intestine [47], suggesting that concentrations of SCFAA are probably much lower than in the large bowel. The same considerations apply to sulphate and succinate, two divalent oxy-anions that will compete with phosphate for uptake by sevelamer, but which like SCFAA are products of the metabolism of intestinal bacteria. If the concentrations of these anions are indeed low at the ileal site of phosphate absorption, they would not provide overriding competition for the exchange sites on a resin, and so would not seriously diminish the resins's capacity to take up phosphate anion and so reduce its mucosal absorption. The phosphate attached to resin in the small intestine is likely to be displaced in the large intestine by SCFAA generated by bacteria, so an analysis of the phosphate bound to resin passed in stool might provide a misleadingly low measure of the resin's capacity to reduce intestinal phosphate absorption, and a complete analysis of faecal phosphate would be necessary to show the resin's full effect. This consideration is not just theoretical, for in a study of faecal anions during administration of a polystyrene quaternary ammonium strong base anion-exchange resin, the increase in total faecal phosphate attributable to the resin was twice as great (at $0.033 \mathrm{mmol}$ phosphate/g of resin) as the mean phosphate content of resin isolated from the stool [20].

Renal failure might itself influence the anionic composition of gastrointestinal fluids, so altering the extent to which anion-exchange resins might sequester phosphate. Salivary phosphate concentrations are increased in renal failure [32, 33], regardless of whether patients are dialyzed or not, with mean concentrations of $8-10 \mathrm{mmol} /$ 1 (3-5 $\mathrm{mmol} / \mathrm{l}$ above normal values), but it is not known 
whether phosphate concentrations in the small intestine are raised in renal failure; however, a study of faecal dialysate from uraemic subjects [48] showed phosphate and SCFAA concentrations within the normal range. Uraemic subjects, including those on dialysis, have greatly increased bacterial counts in their small intestine, with significant contamination of the jejunum and duodenum [49], increasing the possibility of significant competition by SCFAA, sulphate and succinate for uptake by resin at the site where phosphate is normally absorbed.

\section{Structure and Properties of Anion-Exchange Resins}

Organic ion-exchange resins are synthetic polymeric carbon compounds on which are attached ionizable groups, which in an aqueous environment dissociate and undergo ion-exchange with ions in the external solution. Anion-exchange resins are classified as being strongly basic or weakly basic, and in either case their ionic forms comprise a fixed positively charged cation (fixed ion) and a mobile freely exchangeable anion (counter ion).

The term 'strongly basic' is used in the classic electrolyte theory sense, meaning that the aqueous resin is fully dissociated at any external $\mathrm{pH}$ and reacts as a base (alkali) in its hydroxide form. The fixed cationic groups are commonly tri-alkyl (type 1), or dialkylethanolamine (type 2), substituted quaternary ammonium groups.

In weakly basic anion-exchange resins the functional groups are primary, secondary or tertiary amines. By way of contrast with 'strongly basic', 'weakly basic' means little or no dissociation of the functional group, and no ability to exist, in a strongly alkaline form. Therefore the dissociation and subsequent ion-exchange properties of weakly basic ion-exchange resins are somewhat difficult to appreciate at first sight as no obvious ionization path is evident from their free amine structure. Weak-base ion-exchange resins function fully only at low $\mathrm{pH}(\mathrm{pH}<$ 4) through the complete protonation of the free amine groups to form the fixed cation and exchangeable counter ion. For example, with hydrochloric acid a weak-base amine is converted to its chloride, or more correctly 'hydrochloride form', as illustrated by the equation below for a primary amine $\left(\mathrm{R}-\mathrm{NH}_{2}\right)$, where $(\mathrm{R}-)$ represents the polymer matrix:

$$
\begin{aligned}
& \begin{array}{l}
\mathrm{R}-\mathrm{NH}_{2} \\
(\text { resin }- \text { free base form) }
\end{array} \\
& \begin{array}{l}
\mathrm{R}-\mathrm{N}^{+} \mathrm{H}_{3} \cdot \mathrm{Cl}^{-} \\
(\text {resin }- \text { chloride form) }
\end{array}
\end{aligned}
$$

Ion-Exchange Resins for

Hyperphosphataemia
Provided the external $\mathrm{pH}$ is low enough to sustain full $(\mathrm{pH}<4)$ or at least partial $(4<\mathrm{pH}<9)$ protonation of the amine group, ion exchange with chloride ion can occur. For example with divalent monohydrogenphosphate anion, $\left(\mathrm{HPO}_{4}^{2-}\right)$ :

$$
\begin{aligned}
& 2\left(\mathrm{R}-\mathrm{N}^{+} \mathrm{H}_{3} \mathrm{Cl}^{-}\right) \\
& (\text {resin }- \text { chloride form) } \\
& \left(\mathrm{R}-\mathrm{N}^{+} \mathrm{H}_{3} \cdot\right)_{2} \mathrm{HPO}_{4}{ }^{2-}+2 \mathrm{Cl}^{-} \\
& (\text {resin }- \text { divalent phosphate form) }
\end{aligned}
$$

Notice that ion exchange is an equilibrium reaction, the position of which is governed by the affinity of the resin for a given ion, and that ion exchange must obey 'the law of chemical equivalents'.

At high $\mathrm{pH}$ weakly basic resins lose their ion exchange function, reverting back to the free base form. The loss of activity with increasing $\mathrm{pH}$ is progressive rather than sudden, depending upon the basicity of a given resin; however most weak base resins would be largely ineffective as ion exchangers above $\mathrm{pH} 9$.

$$
\begin{aligned}
& \mathrm{R}_{-} \mathrm{N}^{+} \mathrm{H}_{3} \cdot \mathrm{Cl}^{-} \\
& \text {(resin }- \text { chloride form) }
\end{aligned}+\underset{(\text { high } \mathrm{pH})}{\mathrm{NaOH}} \rightarrow \underset{(\text { resin }- \text { free base form })}{\mathrm{R}-\mathrm{NH}_{2}+\mathrm{NaCl}+\mathrm{H}_{2} \mathrm{O}}
$$

The features of an anion-exchange resin that mainly determine its ion-exchange properties are as follows.

\section{(1) Anion-Exchange Capacity}

This is the total quantity of exchangeable ions per unit mass (or volume) of a resin in a specified form (usually chloride). It varies with resin type and structure and is usually within the range of $3-10 \mathrm{mEq} / \mathrm{g}$ of dried resin, being greater in resins in which active sites are closer together and so more tightly packed, though steric hindrance places a limit on what synthesis can achieve. Many resins contain bulky aromatic groups which, because of the space they occupy, limit the anion-exchange capacity of the resin. Over the years improvements in synthesis routes have ensured that most modern commercial products have a regular structure and consistent exchange capacity. From the physician's viewpoint, the higher the available capacity of a resin, the lower the dose that will be required for clinical effect.

\section{(2) Relative Anion-Affinity of the Resin}

The intrinsic affinity of an anion-exchange resin for different anions varies with the basicity of the resin's functional groups, and for a given resin tends to increase with increasing valency and increasing size of the anion. Strongly basic resins are fully ionized at all $\mathrm{pH}$ values and around neutral $\mathrm{pH}$ the order of relative affinity of 
the resin for different anions of physiological importance is:

$$
\mathrm{OH}^{-}<\mathrm{HCO}_{3}^{-}<\mathrm{Cl}^{-}<\mathrm{H}_{2} \mathrm{PO}_{4}^{-}<\mathrm{HPO}_{4}^{2-}<\mathrm{SO}_{4}^{2-}
$$

Equilibrium in mixed valency ion exchange systems is greatly influenced by the total ion concentration in solution, multivalent ions being increasingly preferred over monovalent ions as the total ion concentration decreases, a phenomenon known as 'electroselectivity' [13]. Apart from the simplest univalent anions, most anions are not highly hydrated, and become less so with increasing size, with anions of the strongest parent acid (lowest $\mathrm{pK}$ ) being usually preferred by the resin phase. However, the overall picture remains complex; for example, the normal hydrogen-bonded structure of the external water is enhanced by the intrusion of large ions of low field strength (ion charge divided by radius) such that they are repelled from the external aqueous solution and forced into the resin phase. This mechanism has been termed 'hydrophobic bonding' [50] and 'water-structure-enforced ion pairing' $[14,51]$ and is thought to explain the high affinity shown by anion-exchange resins for many inorganic poly-atomic anions and large organic anions.

A resin's ion-exchange affinity towards large organic anions, including SCFAA, may be enhanced by a similar contribution due to intermolecular van der Waals type absorption between the organic polymer matrix of the resin and the structural hydrocarbon component of the organic anion. For a given resin this effect increases both with increasing molecular mass of the organic anion and also where there is structural similarity, either both aliphatic or both aromatic, between the resin and organic anion [52].

The above considerations also apply to weak-base resins except that the relative affinities observed are very $\mathrm{pH}$ dependent, there being no universal sequence. Generally, their relative affinity for the anions of strong acids (anions of low $\mathrm{pK}$ value) is greater than that of strongly basic resins, although around neutral $\mathrm{pH}$ the order stays the same:

$$
\mathrm{HCO}_{3}^{-}<<\mathrm{Cl}^{-}<\mathrm{H}_{2} \mathrm{PO}_{4}^{-}<\mathrm{HPO}_{4}^{2-}<\mathrm{SO}_{4}^{2-}
$$

Conventional weak-base resins show little ion exchange affinity towards anions of weak parent acids, for example bicarbonate/carbonic acid. Their affinity towards other weak acid anions, such as acetate, propionate and succinate, depends on the $\mathrm{pK}$ values of both the parent acid and the resin concerned. At increasingly alkaline $\mathrm{pH}$ values a weak-base resin progressively converts to its free base form, eventually losing its ion exchange properties completely. Thus any anion that exists only at high $\mathrm{pH}$, such as hydroxide $\left(\mathrm{OH}^{-}\right)$, trivalent phosphate $\left(\mathrm{PO}_{4}^{3-}\right)$ or divalent carbonate $\left(\mathrm{CO}_{3}^{2-}\right)$ cannot be taken up by a weak-base resin since at this $\mathrm{pH}$ the resin has reverted to its free base unionized form. The dissociation properties of any weak-base resin are governed by the $\mathrm{pH}$ within the resin, which in turn is a function of complex polyelectrolyte interactions $[13,53]$. Simplistically, a weak-base resin becomes progressively more inactive as the external $\mathrm{pH}$ becomes numerically greater than the $\mathrm{pK}$ value of its functional groups, which typically lie in the $\mathrm{pH}$ range 6-9.

\section{(3) Proximity of Active Exchange Sites}

Clearly an anion entering a resin will share its charges optimally with the monovalent charges of the fixed cations. For the exchange of monovalent anions the configuration of the resin sites is of minor importance. However, for divalent anions such as sulphate and monohydrogen phosphate, the situation is different. Firstly, the number of stereochemical ways that a divalent anion can share its charges with a dispersed array of monovalent resin exchange sites is greater than the number of configurations open to a monovalent anion. Thermodynamically this is equivalent to an increase in configurational entropy of the system, and therefore a preference by a resin for divalent over monovalent ions. Secondly, a dense population of univalent exchange sites (close proximity) on the resin more readily favours site charge sharing with a divalent anion compared with a sparse and dispersed array of resin sites. This reasoning forms the basis of the 'charge separation theory' first proposed by Clifford and Weber [54] to explain how resin structure and exchange group function influence monovalent over divalent ion selectivity. They found that weakly basic functionality and closely positioned positively charged amine groups forming part of the continuous co-polymer matrix were the two most important factors in enhancing divalent anion preference over monovalent anion. This condition is best met by phenol-formaldehyde polyamine and epoxypolyamine weak-base resins (see below), where phenol and formaldehyde or epichlorohydrin are co-polymerized with polyethyleneamines such as diethylenetriamine and triethylenetetraamine. This gives an active amine nitrogen separation of about $0.45 \mathrm{~nm}$, which is the distance between the two carbon atoms constituting the ethylene group. Structures where the polyamine groups are pendant on the co-polymer structure, whilst not ideal should, if the groups are in close proximity, still show enhanced 
Table 1. Ion exchange requirements for optimum uptake of phosphate in the gut

\begin{tabular}{|c|c|c|}
\hline & Requirement & Benefit \\
\hline 1 & Dilute total external concentration & $\begin{array}{l}\text { Resin selectivity for divalent over monovalent ions increases with decreasing total } \\
\text { external ionic concentration. } \\
\text { NB. Essentially constant for intestinal juices at } \sim 300-400 \mathrm{meq} / \mathrm{l} \text {. }\end{array}$ \\
\hline 2 & $\begin{array}{l}\text { High dry weight ion exchange capacity } \\
\text { (meq/dry g) }\end{array}$ & $\begin{array}{l}\text { Close proximity of exchange sites that thermodynamically favours the uptake } \\
\text { of divalent over monovalent ion. }\end{array}$ \\
\hline 3 & $\begin{array}{l}\text { Continuous rather than pendant } \\
\text { configuration of resin exchange groups }\end{array}$ & Potentially greater dry weight capacity (see table 2 ). \\
\hline 4 & Small functional group & Potentially greater dry weight capacity (see table 2 ). \\
\hline 5 & Low resin cross-linking & $\begin{array}{l}\text { Allows resin swelling and changes in co-polymer configuration for optimum uptake of } \\
\text { divalent mono-hydrogenphosphate anion. }\end{array}$ \\
\hline 6 & $\begin{array}{l}\text { Weakly basic polyamine functional } \\
\text { group }\end{array}$ & $\begin{array}{l}\text { Only weakly basic polyamine resins have a sufficiently high dry weight capacity } \\
\text { (see table 2). } \\
\text { Lower affinity for SCFAA compared with strong base resins. }\end{array}$ \\
\hline 7 & $5<$ external $\mathrm{pH}<<9$ & $\begin{array}{l}\text { Optimum for the formation of the preferred divalent mono-hydrogenphosphate anion } \\
(\mathrm{pH}>5) \text { whilst retaining weak-base resin capacity }(\mathrm{pH}<<9) .\end{array}$ \\
\hline 8 & Aromatic resin structure & Weaker van der Waals absorption of SCFAA. \\
\hline
\end{tabular}

affinity for divalent over monovalent anions. A low degree of cross-linking might be expected to have an influence by allowing more flexibility of the co-polymer structure, thereby achieving the optimal exchange site configuration.

Consideration of basicity, co-polymer structure and the distance between exchange groups (dry weight capacity) should thus be the basis for predicting the optimum selectivity of a resin for phosphate uptake. Table 1 provides a summary of this section, detailing the desirable features of a resin for predicting maximum selectivity towards divalent phosphate.

\section{Characteristics of Individual Resins}

From the above considerations, which we summarize in table 1 , the ideal resin for phosphate sequestration should be strongly basic (and so effective at all $\mathrm{pH}$ values) and should have a polymer structure of continuous closely positioned exchange sites to ensure a high exchange capacity and to favour uptake of divalent phosphate. Finally its structure should be predominantly aromatic in order to suppress van der Waals absorption of SCFAA. Currently such a resin does not exist; in particular steric hindrance has prevented synthesis of resins containing

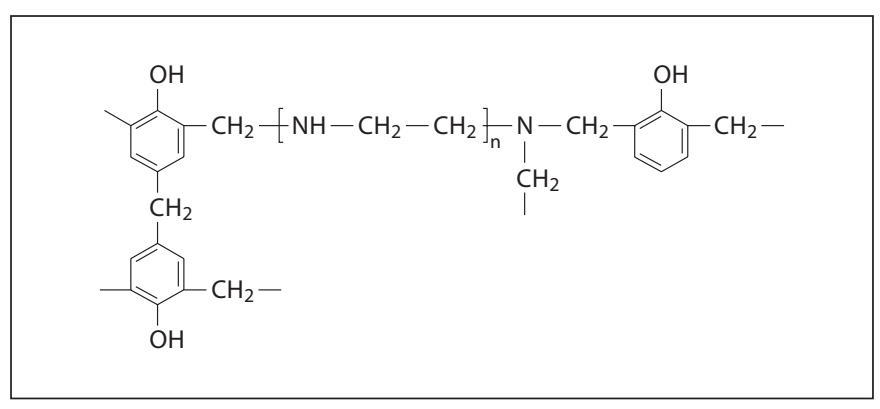

Fig. 1. Phenylpolyethyleneamine (methanal) resin.

strongly basic exchange groups in close proximity to each other. One therefore has to consider other resins, particularly weakly basic ones, that promise well for phosphate uptake, although they are less than ideal.

Figures 1-7 show the basic structure of several typical anion-exchange resins that are commercially available or could readily be manufactured; several are already in clinical use. Almost all are weak-base polyamine resins, shown in their uncharged free base form, except for resin no. 3 (fig. 3), which is a wholly strong-base quaternary ammonium resin, and resin no. 4 (fig. 4 ), which is a weakbase polyamine resin containing a small fraction of qua- 


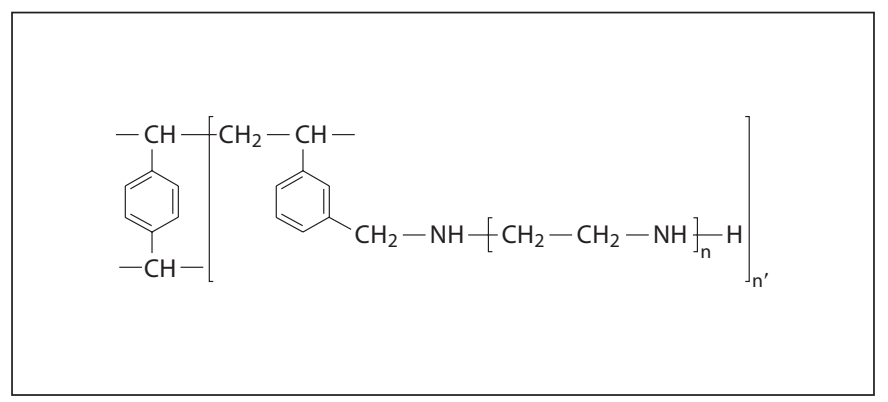

Fig. 2. Ethenylbenzene polyethyleneamine (diethenylbenzene) resin.

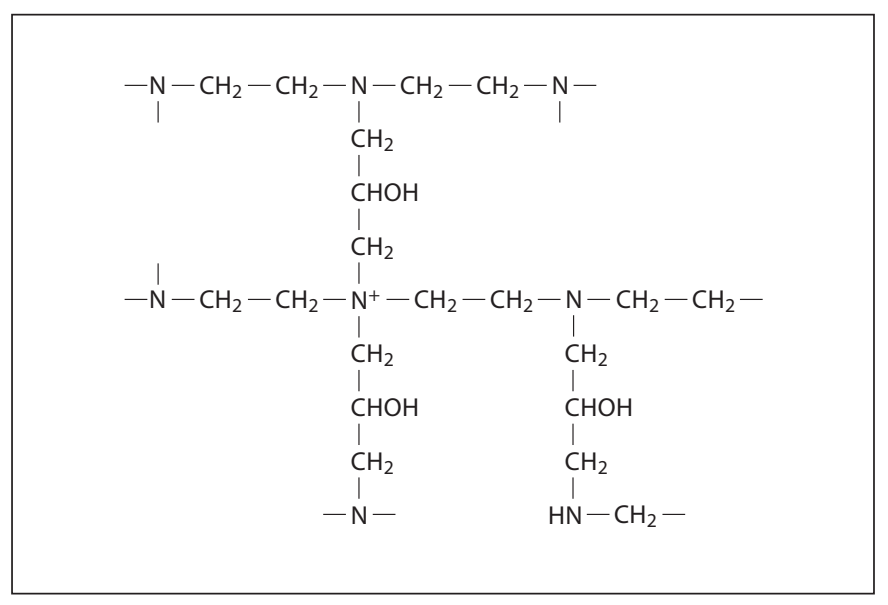

Fig. 4. Polyethyleneamine (epichlorohydrin) resin: colestipol.

ternary strong-base groups. The chemical name used to designate a resin is usually derived from the monomers and method of polymerization used in its synthesis, and may not always be apparent in its final structure. Some of these resins have been used to sequester bile anions by absorption and anion exchange of the carboxyl or sulphonate groups of the glycine- or taurine-bound primary bile acids anions.

The word in parentheses in each figure legend is the cross-linking agent employed. Cross-linking holds the polymer chains of a resin together, controlling both its physical strength and porosity; the extent of cross-linking can be varied in synthesis from very low cross-linking, giving a micro-porous soft material, to very high cross-linking and a dense hard structure with macroscopic pores and channels. Cross-linking and the presence of hydrophilic groups (functional groups and ex-
Fig. 3. Ethenylbenzene quaternary ammonium (diethenylbenzene) resin: colestyramine.

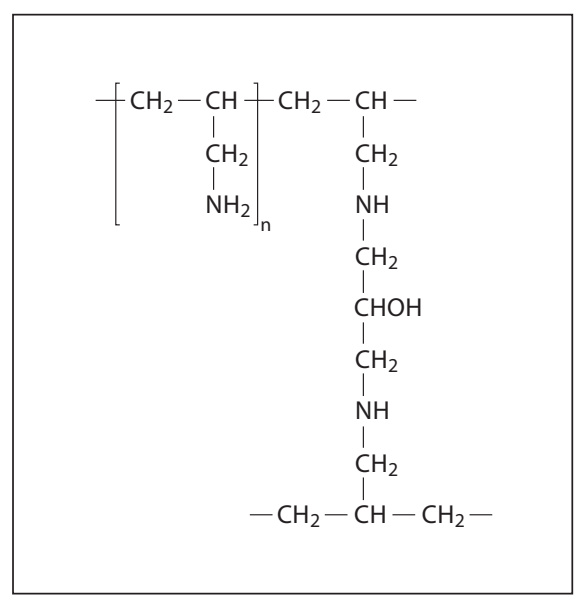

Fig. 5. Polyallylamine (epichlorohydrin) resin: sevelamer.

changeable ions) within the resin determine the extent of hydration. A resin for clinical use may take the form of a hygroscopic granular solid (colestipol and colestyramine) or a gel/tablet (sevelamer and colesevelam), factors that may be important in influencing palatability and intestinal side effects.

Figure 1 shows the general structure of one of the earliest weakly basic resins to be synthesized, a condensation co-polymer of phenylpolyethyleneamine and methanal (phenol-formaldehyde). The resin Amberlite ${ }^{\circledR}$ IRP58, manufactured by Rohm and Haas, was of this type and was used in the early treatment of gastric acidity in ulcer patients $[17,18]$, and later as a carrier for anionic drugs such as para-aminosalicylic acid [55]. The total ion exchange capacity of this type of resin is high, around 10 $\mathrm{mEq} / \mathrm{g}$ of dried resin in the chloride form, in keeping with the close proximity of its polyamine exchange sites. One 


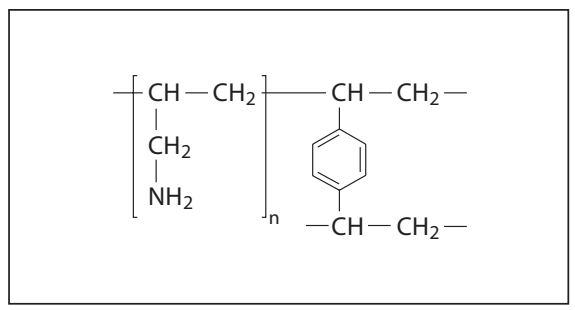

Fig. 6. Acrylic polyamine (diethenylbenzene) resin.

would predict both a high selectivity towards divalent phosphate over monovalent anions, and its aromatic copolymer structure favouring weaker van der Waals absorption of aliphatic SCFAA.

Figure 2 shows a more recently introduced vinyl polymerized weakly basic ethenylbenzene/diethenyl-benzene(styrene/divinylbenzene) polyamine resin, which has not been used clinically. Here the polyethyleneamine groups are pendant on the polymer chain and therefore not as ideally placed as when forming part of the continuous co-polymer structure. Nevertheless, such a resin should still show a favourable selectivity towards divalent phosphate, whilst its aromatic structure would be expected to demonstrate some resistance towards van der Waals absorption of SCFAA.

Figure 3 shows colestyramine, an ethenylbenzene/diethenylbenzene (styrene/divinylbenzene) vinyl polymerized resin containing strongly basic quaternary ammonium groups that are widely spaced, on pendant benzyl groups, at ten carbon atoms apart. There are no weak base groups and no polyamine structure. This resin was introduced clinically as a bile anion sequestrant almost 50 years ago $[21,22]$ but has not been employed as a phosphate sequestrant. Its structure and relatively low exchange capacity (about $4 \mathrm{mEq} / \mathrm{g}$ in the dried chloride form) would predict a relatively poor selectivity for divalent over monovalent anions, as found by Clifford and Weber [54]. Although its strong base property would favour an increase in ion exchange affinity for SCFAA, which is a disadvantage, this is off-set by a weaker van der Waals absorption of SCFAA due to its aromatic structure. A 1963 study [20] of a similar resin in man showed poor gastrointestinal uptake of phosphate compared with organic anion, as discussed below.

Figure 4 depicts colestipol, a totally aliphatic epoxypolyamine resin formed by the condensation co-polymerization of diethylenetriamine with epichlorhydrin(3chloro-1:2-epoxy-propane), the chlorine is eliminated as hydrogen chloride during the reaction. This resin was introduced clinically as a bile anion sequestrant in 1970 [56, 57] and mainly incorporates continuous polymeric weakly basic tertiary amine groups separated by only two carbon atoms, and some strongly basic quaternary ammonium groups. The measured total chloride capacity of the dried resin is about $7.3 \mathrm{mEq} / \mathrm{g}$, with about 13\% strongbase quaternary ammonium group capacity. Such a resin has nearly all the attributes to show favourable uptake of divalent phosphate over monovalent anions, its totally aliphatic structure being the most significant negative characteristic in terms of competition from SCFAA uptake.

Figure 5 represents the free base form of sevelamer, a vinyl polymerized allylamine (2-propenylamine) resin cross-linked with epichlorhydrin (3-chloro-1:2-epoxypropane). This is an aliphatic wholly weakly basic resin with primary and secondary amine groups that are 3-5 carbon atoms apart [10]. The exchange site density is high, as shown by a theoretical chloride capacity of 10.7 $\mathrm{mEq} / \mathrm{g}$ of dried resin; this is in close agreement with a measured value for the totally converted chloride form of $9.9 \mathrm{mEq} / \mathrm{dry}$ g. The resin would be expected to show high selectivity towards divalent phosphate ions, but the presence of pendant rather than continuous functional groups, and its totally aliphatic structure, would appear to lower its potential rating compared with other contenders (see table 2). Although sevelamer has been shown to lower plasma cholesterol fractions in patients receiving it for management of hyperphosphatemia, its manufacturers have also produced a resin (cosevelam) for bile anion sequestration. This product has a similar structure to sevelamer but contains also some strongly basic quaternary ammonium groups which would be expected to be active in the alkaline duodenum where bile enters the intestine.

Figure 6 shows a cross-linked acrylic polyamine resin, so called because it is based on the vinyl co-polymeriza- 
Table 2. Phosphate affinity rating against resin properties

\begin{tabular}{|c|c|c|c|c|c|c|c|c|c|}
\hline \multirow[t]{2}{*}{ Figure number and resin type } & \multicolumn{2}{|c|}{$\begin{array}{l}\text { Polyamine } \\
\text { configuration }\end{array}$} & \multicolumn{2}{|c|}{$\begin{array}{l}\text { Theoretical capacity } \\
\mathrm{mEq} / \mathrm{g}\end{array}$} & \multicolumn{2}{|c|}{ Basicity } & \multicolumn{2}{|c|}{$\begin{array}{l}\text { Co-polymer } \\
\text { structure }\end{array}$} & \multirow[t]{2}{*}{ Score } \\
\hline & $\begin{array}{l}\text { contin. } \\
+2\end{array}$ & $\begin{array}{l}\text { pendant } \\
+1\end{array}$ & $\begin{array}{l}<7 \\
-1\end{array}$ & $\begin{array}{l}>7 \\
+1\end{array}$ & $\begin{array}{l}\text { weak } \\
+1\end{array}$ & $\begin{array}{l}\text { strong } \\
-1\end{array}$ & $\begin{array}{l}\text { aliphatic } \\
-1\end{array}$ & $\begin{array}{l}\text { aromatic } \\
+1\end{array}$ & \\
\hline 1 Phenylpolyamine (methanal) & +2 & & & $9.8(+1)$ & +1 & & & +1 & 5 \\
\hline 2 Polyamine (ethenylbenzene) & & +1 & & $9.1(+1)$ & +1 & & & +1 & 4 \\
\hline 3 Colestyramine (ethenylbenzene quat. ammonium) & & +1 & 4.7( & & & -1 & & +1 & 0 \\
\hline 4 Colestipol (polyamine epichlorohydrin) & +2 & & & $12.6(+1)$ & +1 & & -1 & & 3 \\
\hline 5 Sevelamer (polyallylamine epichlorohydrin) & & +1 & & $10.7(+1)$ & +1 & & -1 & & 2 \\
\hline 6 Acrylic (polyamine diethenylbenzene) & & +1 & & $10.7(+1)$ & +1 & & -1 & & 2 \\
\hline 7 Colestimide (polyimidazole epichlorohydrin) & +2 & & 5.0( & & +1 & & -1 & & 1 \\
\hline
\end{tabular}

tion of an acrylic monomer such as acrylonitrile (propenonitrile) and diethenylbenzene (cross-linking). Final chemical reduction of the nitrile groups produces polyallylamine functionality. Note the similarity to the pendant polyallylamine structure of sevelamer, the only key difference being the nature of the cross-linking agent. The high theoretical chloride form capacity $(10.7 \mathrm{mEq} / \mathrm{g})$ renders resins of this type worthy of further investigation as phosphate-selective exchangers. Not only does this type of resin demonstrate a high selectivity for divalent over monovalent anions [54], but relevance to SCFAA uptake arises from the fact that both weak and strong base aliphatic acrylic anion exchange resins were developed commercially for water treatment because of their better resistance towards irreversible fouling by aromatic 'humic acids' (unidentified organic anions of high molecular weight), in keeping with van der Waals type absorption predictions described earlier [58].

Figure 7 shows a novel imidazole-containing resin, colestimide or colestilan, that has been used in Japan since 1997 as a bile anion-sequestrant [59] and has recently been advocated as an intestinal phosphate binder for patients with end-stage renal failure $[60,61]$. The imidazole groups are weakly basic, with only one of the nitrogen atoms per imidazole ring forming the acid salt form on protonation. The theoretical ion-exchange capacity of the dried chloride form can be calculated as $5 \mathrm{mEq} / \mathrm{g}$, in good agreement with data published by Kurihara et al. [61]. This represents a low amine site density (widely separated exchange sites) and the resin would therefore not be expected to show an enhanced affinity for divalent over monovalent anions compared with the higher capacity resins considered here.
In table 2 each of the resins 1-7 described above are compared according to the characteristics listed in table 1 . Very desirable, desirable and non-desirable qualities are given $a+2,+1$ and -1 rating, respectively. The numbers of ideal and non-ideal characteristics are added up algebraically to give each resin a total score indicating its predicted suitability for phosphate uptake in the alimentary tract. The basis of the comparison is as follows.

(1) Polymer configuration: phosphate uptake is best favoured by a structure where the amine exchange sites are part of the continuous polymer chain $(+2)$ rather than a side-chain (pendant) component $(+1)$.

(2) Theoretical capacity: phosphate affinity is enhanced if the resin has a high exchange capacity (closely situated exchange sites), arbitrarily set at $<7 \mathrm{mEq} / \mathrm{g}(-1)$ and $>7 \mathrm{mEq} / \mathrm{g}(+1)$.

(3) Basicity: the stronger the basicity, the greater a resin's ion exchange affinity for competing SCFAA (-1) compared with weak base resins $(+1)$.

(4) Co-polymer structure: an aromatic structure would show weaker van der Waals attraction of SCFAA $(+1)$ compared with an aliphatic structure $(-1)$.

The calculated ion-exchange capacity values quoted (mEq/g dry weight of resin) are theoretical for the chloride form, based on the ideal repeating polyamine unit cell structure. In practice the measured dry weight capacity is less than theoretical because the latter takes no account of the presence of cross-linking, and in practice it is not usually possible to achieve $100 \%$ amination of the co-polymer. Given the above analysis, the order of predicted preference for phosphate uptake by the ion-exchange resins considered becomes, in descending order: 
$1>2>4$ (colestipol) $>5$ (sevelamer $)$

$=6>7$ (colestimide) $>3$ (colestyramine)

Clinical evaluation and other practical considerations are obviously all important in deciding the best resin for intestinal phosphate sequestration, but these theoretical factors are clearly useful in assessing the potential of existing and future ion exchangers for the treatment of hyperphosphataemia.

\section{Phosphate Uptake by Anion-Exchange Resins: Experimental Evidence}

Before the introduction of sevelamer there were few clinical studies of phosphate uptake by orally administered anion-exchange resins. The first work in man that is known to us was a series of personal experiments published over forty years ago [20]. These studies were not primarily intended to measure removal of phosphate from the body by resin, but to assess whether a resin would remove the inorganic anions retained in uraemic acidosis, i.e. chloride, sulphate and phosphate, and replace these with bicarbonate precursors, so tending to correct systemic acidosis. Normal subjects were stabilized on a constant diet, fed resin for 3-day periods and their faeces collected with the use of faecal markers. Few resins suitable for clinical use were available at the time and the ones used were various forms of polystyrene resin similar to the colestyramine illustrated in figure 3 , containing strongly basic quaternary ammonium groups as their exchange sites and administered in their carbonate or acetate forms. The results were disappointing in that the faecal yield of these inorganic anions was equivalent on average to only one fifth of the resin's theoretical anion-exchange capacity, the main anion uptake being unmeasured organic anion. Phosphate uptake by resin was $0.033 \mathrm{mmol} / \mathrm{g}$ of resin, approximately $1.4 \%$ of the resin's total anion exchange capacity, whereas increased faecal chloride was more than 20 -fold greater at $0.81 \mathrm{mmol} /$ $\mathrm{g}$ resin. Increased faecal sulphate was $0.030 \mathrm{mmol} / \mathrm{g}$ resin, and increased faecal total $\mathrm{CO}_{2}$, presumed to be bicarbonate, $0.74 \mathrm{mmol} / \mathrm{g}$ resin. Increased faecal removal of 'fixed anion' from the body by resin (chloride, phosphate and sulphate) totalled $0.87 \mathrm{mEq} / \mathrm{g}$ resin, and its replacement by bicarbonate precursor (acetate or carbonate in the initial resin) significantly altered systemic acid/base state, as shown by an alkaline diuresis, 24 -hour urine $\mathrm{pH}$ values increasing from a mean of 5.41 to 6.94 , and urinary total hydrogen ion excretion (titratable acid plus ammonium minus bicarbonate) falling by about $60 \mathrm{mmol} /$ day and becoming negative during intake of resin. These observations are of some interest in view of recent findings on the effect of sevelamer on acid/base state, which are discussed below. The minuscule removal of phosphate by resin in these studies can be attributed partly to the use of a resin with a relatively low selectivity for phosphate compared with polyamine resins, but also to the low concentrations of phosphate in the lower intestine, and the presence there of high concentrations of competing organic anion, mainly SCFAA. A useful fall-out from this study was the finding that resins contained in dialysis capsules passing through the gastrointestinal tract would take up diffusible intestinal anions, and were much easier to analyze than whole stool, permitting separate analyses of several different resins swallowed simultaneously; however, as pointed out above, phosphate attached to resin recovered from faeces might give a falsely low estimate of the resin's capacity to sequester phosphate and prevent its absorption in the small intestine.

In 1985 Burt et al. [62, 63] suggested that anion-exchange resins could be used to treat the phosphate retention of renal failure. In vitro studies of five strongly basic Dowex ${ }^{\circledR}$ resins showed that uptake of phosphate from phosphate solutions in simulated gastric or intestinal fluid was independent of the type 1 versus type 2 resin, granule size, or degree of cross-linking of the resin. Unfortunately no studies on animals or man were reported, and we have already noted above that strongly basic resins such as those used in this study are less suitable for intestinal phosphate sequestration than the weakly basic resins that most subsequent workers have used.

Sevelamer was introduced over 1997-1999. Initial in vitro work on the material [9-12] showed a maximum phosphate uptake of $2.4-2.6 \mathrm{mmol} / \mathrm{g}$ of sevelamer gel, greatest at $\mathrm{pH}$ 6-7.5, falling off at both higher and lower $\mathrm{pH}$ values, particularly the former. The reduced affinity at high $\mathrm{pH}$ was attributed to the well-known propensity of weakly basic resins to convert to the undissociated free base form at $\mathrm{pH}$ values above their $\mathrm{pK}$ value; at lower $\mathrm{pH}$ values the progressive reduction in phosphate affinity was attributed to the phosphate ion being progressively converted to its monovalent form. Sevelamer was shown to have a much higher affinity for phosphate than for chloride or bicarbonate [10], which the authors suggested was due to the proximity of the exchange sites in the polymer being sufficiently close in some configurations of the polymer for individual exchange sites to bind to both anionic sites in the divalent form of the phosphate ion. No studies were reported comparing sevelamer's uptake of 
phosphate with that of SCFAA, sulphate or succinate. The authors suggested that hydrogen bonding between phosphate anion and the resin was a factor enhancing phosphate uptake. However, classical hydrogen bonding between oxy-anions and a resin's exchange sites is not considered to be a pertinent mechanism in ion-exchange reactions; if it were, one would expect a more favourable uptake of oxy-anions in the gut that are known to have no, or very weak, affinity for weak base anion exchange resins, for example bicarbonate.

The first published animal studies of sevelamer were on rats fed approximately $300 \mathrm{mg} /$ day of phosphorus (a very large intake for a rat) with urinary excretory rates approximating $200 \mathrm{mg} /$ day. When animals were fed chow containing up to $9 \%$ by weight of sevelamer, urinary phosphate decreased impressively in a dose-dependent manner, up to a maximum reduction of $96 \%$ [11]. Unfortunately no measurements of faecal or blood phosphate were recorded, nor details of dietary rejects, so it is difficult to know how much of the reduction in urinary phosphate was caused by increased faecal loss of phosphate.

A later study on rats included faecal phosphate measurements and compared the effects of an oral sevelamerlike polyallyl resin (PAA-B), with those of a strongly basic polystyrene resin (Dowex ${ }^{\circledR} 1 \mathrm{XB}$ ) of similar structure to the colestyramine shown in figure 3 [64]. Initial in vitro studies showed that PAA-B sequestered $4.4 \mathrm{mmol}$ phosphate/g resin, about three times as much as Dowex $1 \mathrm{XB}$. When rats were fed $1 \mathrm{~g}$ daily of resin in their chow for three days, the increase in faecal phosphate in the PAAA-B-fed animals was about $2.6 \mathrm{mmol} / \mathrm{g}$ resin, more than twice the faecal phosphate excess $(1.1 \mathrm{mmol} / \mathrm{g}$ resin) of animals taking Dowex ${ }^{\circledR} 1 \mathrm{XB}$, and urinary phosphate excretion showed reciprocal changes.

A single balance study on normal humans taking sevelamer has been reported [12], in which twenty-four healthy subjects were involved; three groups of 6 each consumed sevelamer at doses of 1.5, 2.5 and $5.0 \mathrm{~g} 3$ times daily respectively, and 6 received placebo. Subjects received 'a phosphate-controlled diet designed to provide $37.5 \mathrm{mmol}$ of elemental phosphorus $(1,200 \mathrm{mg}) /$ day'. After a control period of 4 days, 24-hour samples of urine and faeces were collected for a further 4 days to provide normal data. Sevelamer or placebo was then given for a further 8 days, on the last 4 of which further urines and faeces were collected to provide experimental data. Mean serum phosphorus was not altered by sevelamer administration, but urinary total phosphorus was significantly reduced at all sevelamer dosages, the reduction roughly in proportion to the sevelamer intake, and excretion falling by a mean of $39 \%$ ( $10.6 \mathrm{mmol} /$ day $)$ at the largest dose level. Faecal studies were less satisfactory, owing perhaps to the use of short faecal collection periods of only $24 \mathrm{~h}$, lack of faecal markers to allocate samples correctly to the experimental protocol, and failure to collect faeces after the last day of sevelamer dosage although normal mean gastrointestinal transit is known to be approximately $48 \mathrm{~h}[65,66]$. Although sevelamer appeared to increase faecal phosphorus, variation between the subjects of each group was so great that intergroup differences failed to reach statistical significance.

Most other reported trials of sevelamer in man have been clinical trials involving administration of the drug to dialyzed patients with renal failure. Trials have lasted up to 2 years [67], the effect of long-term sevelamer usually being compared with a more conventional oral phosphate-binder, most often calcium acetate or carbonate, and the results from two matched groups of patients being assessed from changes in plasma phosphate, calcium times phosphate product $(\mathrm{Ca} \times \mathrm{P})$, and serum parathyroid hormone. Both forms of therapy have been effective in controlling these variables, but on a metric weight for weight basis calcium acetate has $20-30 \%$ more potency than sevelamer and calcium carbonate slightly less than sevelamer, so appropriate adjustments are required in dosage $[68,69]$. These studies yield no quantitative information on sevelamer's uptake of phosphate or competing anions, although clinically useful information has been obtained. In a few trials use of calcium salts has been attended by a significantly higher incidence of adverse cardiovascular events, probably due to a higher incidence of progressive vascular deposition of calcium phosphate $[70,71]$. It is surprising that this complication should arise in patients in whom plasma phosphate and $\mathrm{Ca} \times \mathrm{P}$ product have been controlled by therapy, but it is possible that the use of calcium supplements has been attended by short-lived surges in plasma calcium which have not been detected by monitoring, but yet have been sufficient to lead to worsening vascular calcification. A second possibility is that the bile-anion-sequestering effect of sevelamer has led to a lower incidence of these vascular complications. The most striking comparison between sevelamer and calcium salts has been financial, for at current prices the necessary dosage of sevelamer has been about ten times as costly as calcium salts in the control of hyperphosphataemia, and this is an important factor in leading many nephrologists to regard calcium salts as the preferred treatment [72]. 


\section{Anion-Exchange Resins as Bile Anion Sequestrants}

Several of the anion-exchange resins discussed here (colestyramine, colestipol and the imidazole-containing colestimide) were initially introduced as bile anion sequestrants for the treatment of hypercholesterolaemia [21], as their generic names imply. Sevelamer was not introduced for this purpose but was subsequently shown to have this property $[9,73]$. In view of the tendency of longterm dialysis patients to develop ischaemic heart disease, to which a raised plasma cholesterol may play a contributory role, it is a happy coincidence that the same drugs may be used to lower both plasma phosphate and cholesterol fractions. The action of these resins is probably to sequester bile anions by both intermolecular absorption and anion exchange of the carboxyl or sulphonate groups of the glycine- or taurine-bound primary bile acid anions (pK values approximately 4 and 2, respectively), and is most likely a property of all the anion-exchange resins discussed here. The conjugated bile anions are very large organic (more than 20 carbon atoms) monovalent anions, so the magnitude of preference for one resin compared with another will not be exactly the same as found for the much smaller inorganic divalent phosphate anion. Colestyramine, the first resin to be introduced to sequester bile anions, is well designed for this purpose, as its active sites areall quaternary ammonium, and so active throughout the $\mathrm{pH}$ range. Also its hydrocarbon polymer structure should show some affinity for large organic aliphatic polycyclic molecules through intermolecular van der Waals attraction forces, and its capacity and cross-linking are such as not to sterically hinder the exchange of anions of this very large size.

\section{Sevelamer-Induced Acidosis}

Development of systemic acidosis, or worsening of pre-existing acidosis, has been reported in many patients on long-term dialysis who are given sevelamer [74-77]. Renal failure impairs the normal renal ability to excrete the acid load produced by metabolism, about $60 \mathrm{mmol}$ of hydrogen ion daily, but the tendency of dialyzed patients to acidosis is normally corrected at each dialysis session by the use of a suitable concentration of bicarbonate in the dialysate, usually $32-40 \mathrm{mmol} / \mathrm{l}$, i.e. slightly higher than the normal plasma level. Administration of sevelamer hydrochloride predictably adds to this metabolic acid load, because the resin must inevitably remove some bicarbonate or bicarbonate precursor (mainly SCFAA) from the body and replaces it with chloride [78]. Each molecule of chloride contributed to the body in exchange for bicarbonate or bicarbonate precursor is equivalent to a molecule of hydrochloric acid added to the body, so the tendency of patients on long-term haemodialysis to acidosis is inevitably increased when they take sevelamer.

Theoretically the problem could be countered by an increase in the dialysate concentration of bicarbonate used in each dialysis session. A more fundamental solution, suitable for both dialyzed and non-dialyzed patients, would be the administration of sevelamer, or any other suitable resin, not as the chloride but as the free base form (or combined with a bicarbonate-precursor such as lactate or acetate). Anion-exchange resins have traditionally been synthesized in the chloride form, but the chloride in the current sevelamer preparation is of no benefit to patients with renal failure. A change in the formulation of sevelamer from its current chloride form to sevelamer attached to a bicarbonate precursor would convert an acid load into a mild alkali load. The alkalinizing effect of such a resin was demonstrated in a 1963 study [20] when a polystyrene-based resin in acetate form, given to healthy subjects taking a constant diet, was shown to have a systemic alkalinizing effect with an increased urine $\mathrm{pH}$ and a reduction in urinary hydrogen ion excretion of about $60 \mathrm{mmol}$ for each $100 \mathrm{~g}$ of resin taken. However, when given to patients on long-term dialysis, such a resin would entail minimum risk of systemic alkalosis, for even at a maximum resin dosage of $10 \mathrm{~g} / \mathrm{day}$ the load of bicarbonate precursor delivered to the body would be no greater than the daily endogenous metabolic acid load of about $60 \mathrm{mmol}$; furthermore much of the resin's ion exchange capacity is likely to be excreted in the stool as bicarbonate precursor SCFAA, so entailing no additional alkali load to the body.

Very recently sevelamer in the carbonate form [79] has been introduced to tackle the problem of acidosis. This would be effective in combating acidosis, but there are inherent problems, which need to be addressed, in the preparation and stability of such a material. All weakbase anion-exchange resins, including sevelamer, function through the protonation of amine groups and formation of an appropriate acid salt. The $\mathrm{pK}$ of dilute bicarbonate/carbonate equilibrium is approximately 10.3 [80]. In solutions at this alkaline $\mathrm{pH}$ carbonate and bicarbonate exist in equal concentrations but as the $\mathrm{pH}$ is lowered carbonate progressively converts to bicarbonate ion, becoming virtually absent at and below $\mathrm{pH}$ 8.3. At a $\mathrm{pH}$ high enough to sustain the presence of carbonate ion, weakbase resins would be converted to their free base form, a 
fact supported by the observation that sevelamer in solutions more alkaline than $\mathrm{pH} 8.5-9.0$ converts to its free base form and ceases to act as an anion-exchanger $[10,11]$. Consequently it is difficult to see how a carbonate form of sevelamer could exist, and therefore we suggest that sevelamer 'carbonate' is probably the bicarbonate or partially free base form. At $\mathrm{pH}$ values progressively lower than 8.3 the formation of an acid bicarbonate may be viable depending on the precise $\mathrm{pK}$ of sevelamer. The point may be largely academic, for the resin in free base or bicarbonate form should be equally efficacious in combating systemic acidosis, and the various ionic forms of resin, including the hydrochloride, would not be expected to differ in their behaviour in the gut towards phosphate.

\section{Other Metabolic Effects of Sevelamer}

Sevelamer reduces plasma urate concentrations in dialyzed patients [73], probably by taking up urate (pK 5.7), or a urate precursor, in the gut; in a 2005 study the mean reduction in plasma urate was $0.64 \mathrm{mg} / \mathrm{dl}(38 \mu \mathrm{mol} / \mathrm{l})$ [81]. A recent review [82] explores the potential role of sevelamer in lowering blood levels of other uraemic toxins (reactive oxygen species, indoxyl sulphate, indole, $p$-cresol); however the possibility that other anion-exchange resins would have similar effects has not been addressed.

\section{The Way Ahead}

Sevelamer was introduced over 1997-1999 as a 'metalfree', 'novel phosphate-binding polymer' [10-12]. Although this terminology was not incorrect, it did not make clear that sevelamer is an anion-exchange resin, sharing features with other anion-exchange resins, some of which were already in clinical use but were not mentioned in these reports. We are critical also of the term 'phosphate binder' to describe anion-exchangers as to many readers this usage implies that a resin behaves like aluminium, calcium and lanthanum in forming virtually insoluble salts with phosphate, whereas the phosphate attached to anion-exchange resins can readily be exchanged for other anions, including those in the gastrointestinal tract, depending on physico-chemical factors that are well understood. It would be better to describe anion-exchange resins as phosphate 'sequestrants', a term already applied to resins in their uptake of bile acid anions.
Several of the other anion-exchange resins described here are on a priori grounds (table 2) likely to be efficient intestinal phosphate sequestrants. The ranking order in table 2 suggests that the formaldehyde/phenol and ethenylbenzene-diethynelbenzene/polyamine resins shown as figures 1 and 2 would be best in this respect. However, neither type of resin is currently available in a form suitable for clinical use. Colestipol, which scores slightly less well than these two, is marginally our preferred choice for clinical trial, for it is readily available for clinical use in both granular and tablet form, it has an excellent safety record as a bile anion sequestrant over thirty-five years of use $[56,57]$, and currently costs less than one eighth the cost of sevelamer. [The 2006 British National Formulary cites the price of sevelamer as 85.21 pence $(\$ 1.79) / \mathrm{g}$, colestipol as 10.03 pence $(\$ 0.21) / g]$. Colestipol has a further advantage in that its amine groups are only $20 \%$ protonated [83], so it would contribute less hydrogen chloride to body fluids than the standard form of sevelamer hydrochloride, which is $40 \%$ protonated, and thus be less likely to cause acidosis.

We argue here that the removal of phosphate by anionexchange resins in the gastrointestinal tract would be subject to competition for uptake from several anions for which their affinity has not been tested - SCFAA, because of its very high concentration in the large intestine, many times greater than that of phosphate; and sulphate and succinate, both of which, like phosphate, are divalent oxy-anions for which a resin is likely to show high selectivity. This argument is dependent on the sites in the intestine where these competing anions arise, and whether significant absorption of phosphate occurs at this site or even more distally.

This review makes clear that only fragmentary information is available on the amounts of phosphate taken up by sevelamer during transit through the human gut, although ten years have elapsed since the drug was introduced. Most workers interested in sevelamer have avoided making observations on faecal phosphate excretion, instead relying on long-term clinical studies of plasma calcium and phosphate, $\mathrm{Ca} \times \mathrm{P}$ product and parathyroid hormone, studies that are clinically useful but tell us little of how sevelamer works in the body. What are required are metabolic balance studies of healthy and uraemic subjects, comparing the efficacy of different resins in increasing faecal phosphate, and it would be best to model these on the procedures established over 50 years ago by Albright [84], which were specifically designed to study disturbances of phosphate metabolism. Because of the major influence of dietary phosphorus intake on faecal 
phosphate, and the normal gastrointestinal transit time of over $48 \mathrm{~h}$, these studies require a constant diet for the whole experimental period, faecal collections pooled over several days, preferably in lots of 3 days or more, and faecal specimens allocated to the experimental protocol by the use of faecal markers. Orally administered dialysis sacs containing resins have been successfully used as a short-cut in the measurement of alimentary 'ion binding' by both anion- and cation-exchange resins $[20,85]$. This is a technique that is easily performed, but as explained above the amount of phosphate attached to a resin passed in the stool might not show the full extent to which the resin has reduced phosphate absorption in the small intestine. The necessary full balance studies are laborious and time consuming, but have yielded vital information on other diseases of phosphate metabolism. In this review we summarized the theoretical background, which will help investigators to decide on their choice of resins to study, but the final decision on the best resin for phosphate sequestration may depend on innovative advances in anion-exchange resin synthesis and on obtaining reliable metabolic balance data from man which are still unavailable.

\section{Acknowledgement}

We are grateful to Dr. S.K. Burke for a supply of sevelamer hydrochloride.

\section{Addendum: Oxalate Binding in the Gut}

It has been suggested that oral anion-exchange resins might be used in the treatment of enteric hyperoxaluria. An initial trial of colestyramine in 1972 [23] was encouraging, but later use of this resin treatment was disappointing, and it is now seldom used. Oxalate is divalent, with two adjacent carboxyl groups of sufficiently low pK (1.2 and 4.2) to be completely ionized at all $\mathrm{pH}$ values existing in the intestine. Anion-exchange resins might reduce intestinal oxalate absorption by (1) sequestering bile anions in the intestine, thus countering their known effect in enhancing mucosal permeability, and by (2) directly sequestering oxalate anion. The latter effect would be optimum with resins with the most closely appositioned exchange groups, such as those shown in figures 1, 2 and 4 (colestipol). In fact, a 1981 study comparing uptake of oxalate by various resins [Laker MF, Hoffman AF: Effective therapy of enteric hyperoxaluria: in vitro binding of oxalate by anion-exchange resins and aluminum hydroxide. J Pharmaceut Sci 1981;70:1065-1067] showed excellent uptake by colestipol, and negligible uptake by colestyramine when chloride was present, as would be predicted by the Clifford/Weber hypothesis [54].

\section{References}

1 Ansell D, Feest T, Rao AVR, Williams A, Winearls C: Eighth Annual report. Bristol, UK Renal Registry, 2005.

-2 Block GA, Klassen PS, Lazarus GM, Ofsthun N, Lowrie EG, Chertow GM: Mineral metabolism, mortality, and morbidity in maintenance hemodialysis. J Am Soc Nephrol 2004; 15:2208-2218.

3 Qunibi WY: Consequences of hyperphosphatemia in patients with end-stage renal disease (ESRD). Kidney Int 2004;66(suppl 90):S8-S12.

4 London GM, Marchais SJ, Guérin AP, Métivier F: Arteriosclerosis, vascular calcifications and cardiovascular disease in uremia. Curr Opin Nephrol Hypertens 2005; 14:525531.

5 Jean G, Chazot C, Charra B: Hyperphosphataemia and related mortality. Nephrol Dial Transplant 2006;21:273-280.

-6 Kestenbaum B, Sampson JN, Rudser KD, Patterson DJ, Seliger SL, Young B, Sherrard DJ, Andress DL: Serum phosphate levels and mortality risk among people with chronic kidney disease. J Am Soc Nephrol 2005;16: 520-528.

7 Gilbertson DT, Liu J, Xue JL, Louis TA, Solid CA, Ebben JP, Collins AJ: Projecting the number of patients with end-stage renal disease in the United States to the year 2015. J Am Soc Nephrol 2005;16:3736-3741.
8 Grassman A, Gioberge S, Moeller S, Brown G: ESRD patients in 2004; global overview of patient numbers, treatment modalities and associated trends. Nephrol Dial Transplant 2005;20:2587-2593.

-9 Chertow GM, Burke SK, Lazarus JM, Stenzel $\mathrm{KH}$, Wombolt D, Goldberg D, Bonventre JV, Slatopolsky E: Polyallylamine hydrochloride (RenaGel): a noncalcemic phosphate binder for the treatment of hyperphosphatemia in chronic renal failure. Am J Kidney Dis 1997; 29:66-71.

10 Holmes-Farley SR, Mandeville WH, Ward J, Miller KL: Design and characterization of sevelamer hydrochloride: a novel phosphate-binding pharmaceutical. J Macromol Sci Pure Appl Chem 1999;A36:10851091.

11 Rosenbaum DP, Holmes-Farley SR, Mandeville WH, Pitruzzello M, Goldberg DI: Effect of RenaGel ${ }^{\circledR}$, a non-absorbable, cross-linked, polymeric phosphate binder, on urinary phosphate excretion in rats. Nephrol Dial Transplant 1997;12:961-964.

12 Burke SK, Slatopolsky EA, Goldberg DI: RenaGel ${ }^{\circledR}$, a novel calcium- and aluminum-free phosphate binder, inhibits phosphate absorption in normal volunteers. Nephrol Dial Transplant 1997;12:1640-1644.

13 Helfferich F: Ion Exchange. New York, McGraw-Hill, 1962.
14 Harland CE: Ion Exchange: Theory and Practice, ed 2. Cambridge, Royal Society of Chemistry, 1994.

15 Dorfner K: Synthetic ion exchange resins; in Dorfner K (ed): Ion Exchangers. Berlin, de Gruyter, 1991, pp 189-396.

16 Wheaton RM, Hatch MJ: Synthesis of ion exchange resins; in Marinsky JA (ed): Ion Exchange: A Series of Advances, vol 2. New York, Dekker, 1991, pp 191-234.

17 Martin GJ, Wilkinson J: The neutralization of gastric acidity with anion exchange resins. Gastroenterology 1946;6:315-323.

18 Wirts CW, Rehfuss ME: A study of the effect of an anion exchange resin on gastric and duodenal secretions and gastric emptying. J Clin Invest 1950;29:37-45.

19 Greenman L, Frey WA, Lewis RE, Sakol MJ, Danowski TS: Biochemical changes in serum and feces during ingestion of carboxylic, sulphonic and anion-exchange resins. J Lab Clin Med 1953;41:236-247.

$>20$ Hurst PE, Morrison RBI, Timoner J, Metcalfe-Gibson A, Wrong O: The effect of oral anion exchange resins on faecal anions. Comparison with calcium salts and aluminium hydroxide. Clin Sci 1963;24:187-200.

21 Bergen SS, Van Italie YB, Tennent DM, Sebrell WH: Effect of an anion exchange resin on serum cholesterol in man. Proc Soc Exp Biol Med 1959;102:676-678. 
22 Carey JB, Williams G: Relief of pruritus of jaundice with a bile-acid sequestering resin. J Am Med Assoc 1961;176:432-435.

23 Smith LH, Fromm H, Hofmann AF: Acquired hyperoxaluria, nephrolithiasis and intestinal disease. New Engl J Med 1972; 286:1371-1375.

24 Clark WM: Topics in Physical Chemistry. Baltimore, Williams and Wilkins, 1952.

25 Hazell T: Minerals in foods: dietary sources, chemical forms, interactions and bioavailability. World Rev Nutr Diet 1985;46:1-123.

26 Calvo MS, Park YK: Changing phosphorus content of the US diet: potential for adverse effect on bone. J Nutr 1996;126:1168S1180 S.

27 Hunt CD, Meacham SL: Aluminum, boron, calcium, copper, iron, magnesium, manganese, molybdenum, phosphorus, potassium, sodium and zinc concentrations in common western foods and estimated daily intakes of infants, toddlers, and male and female adolescents, adults and seniors in the United States. J Am Diet Assoc 2001;101:10581060.

28 Rimington C, Kay HD: Some phosphorus compounds of milk. 2. The liberation of phosphorus from caseinogen by enzymes and other agents. Biochem J 1926;20:777790.

-29 Karr WG, Abbott WO: Intubation studies on the human small intestine. 4. Chemical characteristics of the intestinal contents in the fasting state and as influenced by the administration of acids, of alkalis, and of water. J Clin Invest 1935; 14:893-900.

30 Altman PL, Dittmer DS: Metabolism. Bethesda, Federation of American Societies for Experimental Biology, 1968.

31 Lura HE: Investigations of the salivary phosphates and phosphatases. J Dent Res 1947;26: 202-224.

- 32 Blum M, ZurkowskyS, Gilad J, Aviram A: Salivary phosphate and calcium concentrations in uraemia. Clin Nephrol 1979;12:191192.

- 33 Savica V, Calò LA, Caldarera R, Cavaleri A, Granata A, Santoro D, Savica R, Muraca U, Mallamace A, Bellinghieri G: Phosphate salivary secretion in hemodialysis patients: implications for the treatment of hyperphosphatemia. Nephron Physiol 2007;105:52-55.

34 Rudd GV: Studies on composition of gastric juice. Part I. Med J Aust 1934;1:431-436.

35 Kogut B, Matzner MJ, Sobel AE: A study of external pancreatic secretions in man. J Clin Invest 1936;15:393-396.

-36 Lee DNB, Walling MW, Gafter U, Silis V, Coburn JW: Calcium and inorganic phosphate transport in rat colon. Dissociated response to 1,25 -dihydroxyvitamin $\mathrm{D}_{3}$. J Clin Invest 1980;65:1326-1331.
37 Danisi G, Murer H: Inorganic phosphate absorption in small intestine; in Handbook of Physiology, ed 2, section 6: The Gastrointestinal System, vol 4; Schultz SG, Field M, Frizzell RA, Rauner BB (sect eds). Bethesda, American Society of Physiology, 1991, pp 323-336.

38 Marks J, Srai SK, Biber J, Murer H, Unwin RJ, Debnam ES: Intestinal phosphate absorption and the effect of Vitamin D: a comparison of rat with mouse. Exp Physiol 2006;91: 531-537.

39 Wrong O, Metcalfe-Gibson A, Morrison RBI, Ng ST, Howard AV: In vivo dialysis of faeces as a method of stool analysis. 1. Technique and results in normal subjects. Clin Sci 1965;28:357-375.

40 Daum K, Tuttle WW, Kisgen R, Imig CJ, Martin C, Klapka MR, Sheehan J, Agle M: Utilization of nitrogen, phosphorus, calcium and iron by men on different breakfasts. J Am Diet Ass 1951;27:475-479.

41 Shohl AT: Mineral Metabolism, New York, Reinhold, 1939

42 Sullivan JF, O'Grady J, Lankford HG: The zinc content of pancreatic secretion. Gastroenterology 1965;48:438-443.

43 Grove EW, Olmsted WH, Koenig K: The effect of diet and catharsis on the lower volatile fatty acids in the stools of normal men. J Biol Chem 1929;85:127-136.

44 Rubinstein R, Howard AV, Wrong OM: In vivo dialysis of faeces as a method of stool analysis. 4. The organic anion component, Clin Sci 1969;37:549-564.

45 Wrong OM, Edmonds CJ, Chadwick VS: The Large Intestine. Its Role in Mammalian $\mathrm{Nu}$ trition and Homeostasis. Lancaster, MTP Press, 1981.

46 Costongs GMPJ, Bos LP, Engels LGJB, Janson PCW: A new method for chemical analysis of faeces. Clin Chim Acta 1985;150:197203.

47 Drasar BS, Hill MJ: Human Intestinal Flora. London, Academic Press, 1974

48 Wilson DR, Ing TS, Metcalfe-Gibson A, Wrong OM: The chemical composition of faeces in uraemia, as revealed by in-vivo faecal dialysis. Clin Sci 1968;35:197-209.

49 Simenhoff ML, Saukkonen JJ, Burke JF, Wesson LG, Schaedler REW, Gordon SJ: Bacterial populations of the small intestine in uremia. Nephron 1978;22:63-68.

50 Franks F: Aqueous solutions of electrolytes in Franks F (ed): Water. London, Royal Society of Chemistry, 1983, pp 57-68.

51 Diamond RM, Whitney DC: Resin selectivity in dilute to concentrated systems; in Marinsky JA (ed): Ion Exchange: A Series of Advances, vol 1. London, Arnold, 1966, pp 277-351.

52 Feitelson J: Interaction between organic ions and ion exchange resins; in Marinsky JA (ed): Ion Exchange: A Series of Advances, vol 2. New York, Dekker, 1969, pp 135-166.
53 Katchalsky A, Michaeli I: Polyelectrolyte gels in salt solutions. J Polym Sci 1955;15:6986.

54 Clifford D, Weber WJ: The determinants of divalent/monovalent selectivity in anion exchangers. Reactive Polym 1983;1:77-89.

55 Dorfner K: Ion exchangers in pharmacy and medicine; in Coers AF (ed): Ion Exchangers: Properties and Applications. Michigan, Ann Arbor Science, 1972, pp 227-236.

56 Parkinson TM, Gundersen K, Nelson NA: Effects of colestipol (U-26,597A), a new bile acid sequestrant, on serum cholesterol in experimental animals and man. Atherosclerosis 1970;11:531-537.

57 Ryan JR, Jain A: The effect of colestipol or cholestyramine on serum cholesterol and triglycerides in a long-term controlled study. J Clin Pharmacol 1972;12:268-273.

58 Tilsley GM: Interactions of organic matter with anion resins. Chem Ind 1979;5:142149.

59 Homma Y, Kobayashi T, Yamaguchi H, Ozawa $\mathrm{H}$, Sakane H, Nakamura H: Specific reduction of plasma large, light low-density lipoprotein by a bile acid sequestering resin, cholebine (MCI-196) in type II hyperlipoproteinaemia. Atherosclerosis 1997; 129: 241-248.

60 Date T, Shigematsu T, Kawashima Y, Satake N, Morita K: Colestimide can be used as a phosphate binder to treat uraemia in end stage renal disease patients. Nephrol Dial Transplant 2003;18(suppl 3):90-93.

61 Kurihara S, Tsuruta Y, Akizawa T: Effect of MCI-196 (colestilan) on hyperphosphataemia in haemodialysis patients: a doubleblind placebo-controlled, short-term trial. Nephrol Dial Transplant 2005;20:424-430.

62 Burt HM, Cameron EC, Leung M, Erber H, Price JDE: In vitro studies using ion exchange resins as potential phosphate binders in renal failure patients. Uremia Invest 1985-86;9:35-44.

63 Burt HM, Cameron EC, Erber H, Price JDE: Ion-exchange resins as potential phosphatebinding agents for renal failure patients: effect of the physicochemical properties of resins on phosphate and bile salt binding. J Pharm Sci 1987;76:379-383.

64 Inoue H, Kagoshima M, Kaibara K: Effects of anion exchange resin as phosphate binder on serum phosphate and iPTH levels in normal rats. Int J Artif Organs 2000;23:243-249.

65 Cummings JH, Jenkins DJA, Wiggins HS: Measurement of the mean transit time of dietary residue through the human gut. Gut 1976;17:210-218.

66 Evans RC, Kamm MA, Hinton JM, LennardJones JE: The normal range and a simple diagram for whole gut transit time. Int J Colorect Dis 1992;7:15-17. 
67 Braun J, Asmus H, Brunkhorst R, Krause R, Schutz W, Neumayer H, Raggi P, Bommer J: Long-term comparison of a calcium-free phosphate binder and calcium carbonatephosphorus metabolism and cardiovascular calcification. Clin Nephrol 2004;62:104116.

68 Emmett M: A comparison of clinically useful phosphorus binders for patients with chronic kidney disease. Kidney Int 2004; 66(suppl 90):S25-S32.

69 Nolan CR, Qunibi WY: Treatment of hyperphosphatemia in patients with chronic kidney disease on maintenance dialysis. Kidney Int 2005;67(suppl 95):S13-S20.

70 Chertow GM, Burke SK, Raggi P: Sevelamer attenuates the progression of coronary and aortic calcification in hemodialysis patients. Kidney Int 2002;62:245-252.

71 Block GA, Spiegel DM, Ehrlich J, Mehta R, Lindbergh J, Dreisbach A, Raggi P: Effect of sevelamer and calcium on coronary artery calcification in patients new to hemodialysis. Kidney Int 2005;68:1815-1824.

72 Hergesell O, Ritz E: Phosphate binders in uraemia: the pharmacodynamics, pharmacoeconomics, pharmacoethics. Nephrol Dial Transplant 2002;17:14-17.
73 Chertow GM, Burke SK, Dillon MA, Slatopolsky E: Long-term effects of sevelamer on the calcium $\times$ phosphate product and lipid profile of haemodialysis patients. Nephrol Dial Transplant 1999;14:2907-2914.

74 Borras M, Marco MP, Fernandez E: Treatment with sevelamer decreases bicarbonate levels in peritoneal dialysis patients. Perit Dial Int 2002;22:737-738.

75 Marco MP, Muray S, Betriu A, Craver L, Belart M, Fernandez E: Treatment with sevelamer decreases bicarbonate levels in hemodialysis patients. Nephron 2002;92:499500.

76 Brezina B, Qunibi WY, Nolan CR: Acid loading during treatment with sevelamer hydrochloride: mechanisms and clinical implications. Kidney Int 2004;66(suppl 90):S39S45.

77 Sonikian MA, Pani IT, Hiopoulos AN, Koutala KG, Marioli SI, Vlassopoulos DA: Metabolic acidosis aggravation and hyperkaliemia in hemodialysis patients treated with sevelamer hydrochloride. Ren Fail 2005;27:143-147.

78 Wrong OM, Harland CE: Sevelamer-induced acidosis. Kidney Int 2005;67:776-777.
79 Duggal A, Hanus M, Zhorov E, Dagher R, Plone MA, Goldberg J, Burke SK: Novel dosage forms and regimens for sevelamer-based phosphate binders. J Ren Nutr 2006;16:248252.

80 Vogel AI: A Textbook of Quantitative Inorganic Analysis Including Elementary Instrumental Analysis, ed 3. London, Longmans, 1961.

81 Garg JP, Chasan-Taber S, Blair A, Plone M, Bommer J, Raggi P, Chertow GM: Effect of sevelamer and calcium-based phosphate binders on uric acid concentrations in patients undergoing dialysis. Arthritis Rheum 2005;52:290-295

82 Nikolov IG, Joki N, Maizel J, Lacour B, Drüeke TB, Massy ZA: Pleiotropic effects of the non-calcium phosphate binder sevelamer. Kidney Int Suppl 2006;105:S16-S23.

83 Merck Index, ed 14. Whitehouse Station, Merck and Co., 2006.

84 Reifenstein FC, Albright F, Wells SL: The accumulation, interpretation, and presentation of data pertaining to metabolic balances, notably those of calcium, phosphorus and nitrogen. J Clin Endocrinol 1945;5:367-395.

$>85$ Chugh KS, Swales JD, Brown CL, Wrong OM: Aluminium resin for the treatment of the hyperkalaemia of renal failure. Lancet 1968;ii:952-953. 